\title{
Experimental estimation of energy dissipation in rocking masonry walls restrained by an innovative seismic dissipator (LICORD)
}

\author{
Linda Giresini $^{1}$ (D) $\cdot$ Fabio Solarino ${ }^{1} \cdot$ Francesca Taddei $^{2} \cdot$ Gerhard Mueller $^{2}$
}

Received: 6 August 2020 / Accepted: 1 February 2021 / Published online: 18 February 2021

(c) The Author(s) 2021

\begin{abstract}
This paper presents an innovative anti-seismic device for controlling the out-of-plane rocking motion of masonry walls with traditional tie-rods, called LInear COntrolled Rocking Device (LICORD). LICORD is a low-impact box connected to the extremity of the traditional tie-rod designed to mitigate rocking for medium-high intensity earthquakes. Additionally, the paper widens the knowledge about the dynamic behavior of rocking walls through the interpretation of the results of an extensive experimental campaign performed on masonry specimens composed by clay brick and cementitious mortar. Firstly, the LICORD's single components are tested to identify their stiffness and damping properties. Secondly, free vibration tests provide actual values of coefficients of restitution on free-standing walls and walls restrained by LICORD, where the walls vary for the height to thickness ratio. For the stockier wall, the ratio of experimental/analytical coefficient of restitution varies from 88 to $98 \%$, whereas for the slender wall, the results are less scattered, with a minimum value of $95 \%$ and a maximum value of $96 \%$. The restrained walls are characterized by coefficients of restitution from 5 to $25 \%$ less than the values found for unrestrained walls, depending on the equivalent viscous coefficient of the shock absorbers. Moreover, LICORD demonstrated to properly absorb and damp the oscillations of the wall and control its rocking motion, strongly reducing the number of impacts and the rotation amplitudes up to $70 \%$. Considerations about the effect of one-sided motion on the assessment of coefficient of restitution are also given. The equivalent viscous damping coefficients are observed to be on the range $4 \%$ (unrestrained wall) and 7-20\% for walls restrained by LICORD.
\end{abstract}

Keywords Rigid block · Out-of-plane $\cdot$ Masonry $\cdot$ Dissipator $\cdot$ Coefficient of restitution · Damping coefficient $\cdot$ Shock absorber $\cdot$ Damping ratio $\cdot$ Rocking control

Linda Giresini

linda.giresini@unipi.it

Extended author information available on the last page of the article 


\section{Introduction}

The analysis of out-of-plane (OOP) mechanisms of masonry buildings is a key issue in the seismic vulnerability assessment of existing structures, whose characterization through experimental tests is fundamental for the correct selection of mechanical properties and boundary conditions (Alecci et al. 2019; Alecci et al. 2020). The relevance of OOP mechanisms in brittle and life-threatening collapse patterns of masonry buildings is confirmed by several reconnaissance reports of worldwide seismic events from moderate (Romão et al. (2011)) to strong intensity (D’Ayala and Paganoni 2011; Rai et al. 2015; Htwe Zaw et al. 2016; Brando et al. 2017). Indeed, the lack of proper connections between walls and between walls and horizontal diaphragms (slabs, timber floors, vaults, arches, etc.) causes the triggering of OOP mechanisms (Griffith et al. 2003; Ferreira et al. 2015), generally studied by means of pseudo-static kinematic and dynamic approaches (Casapulla et al. 2017).

The dynamic approaches-also called rocking analyses-were shown to be more conservative than kinematic approaches and more representative of reproducing the actual dynamic motion of rocking masonry walls modelled as rigid blocks (Giresini et al. 2015), even when investigating their potential resonance conditions (Casapulla et al. 2010; Casapulla and Maione 2017). An extended literature is available on the rocking analysis of masonry walls (Lagomarsino 2015), both in free-standing (that is without any restraint) and in restrained conditions. The most common model for rocking masonry consists in a single degree of freedom (SDOF) system rocking about the two corner points (pivot points) on the ground. An additional horizontal restraint allows the simulation of transverse walls, vaults, arches or typical anti-seismic devices such as steel tie-rods (Giresini 2017; Argiento et al. 2019; Casapulla et al. 2019; Giresini et al. 2019a). Often, steel tie-rods apply tensile concentrated forces during motion that could generate localized masonry failures, especially where the assumption of monolithic masonry is not adequate. Moreover, their role can be detrimental since the tie-rods of existing, often historic, buildings, can abruptly undergo brittle failures (Calderini et al. 2016) modifying the motion and inducing unexpected behaviors.

This paper presents an innovative anti-seismic device, called LICORD (LInear COntrolled Rocking Device), designed to overcome these issues by controlling the rocking of masonry walls. This device consists in coupling traditional restraint techniques such as steel tie-rods, frequently used in historic buildings during the last centuries, with an individual or multiple shock absorbers coupled to a re-centering system. When the OOP mode of a wall is activated, LICORD, based on the Damage Avoidance Design (DAD) philosophy, dampens the wall by controlling its rocking motion and limiting the rebound effects on adjacent walls. The idea to couple different dissipation devices in the passive control systems is not entirely new (D'Ayala 2014); for instance, viscous and frictional devices were coupled with base isolation techniques in (Makris and Chang 2000). Also for reinforced concrete frames different isolation systems were coupled, combining rubber based, steel based and shape memory alloy components (Dolce et al. 2007). A similar concept recently arose in devices conceived for the reduction of vibrations on slender and artistic assets where smooth rocking is controlled through visco-elastic dissipators and frictional cylindrical contact surfaces (Froli et al. 2019a,b). The success of these techniques relies on the combination of velocity-dependent (viscous dampers) with displacement-dependent (hysteretic) energy dissipation devices. This aspect is advantageous for self-centering systems to counteract near-fault earthquakes, which are dominated by long period pulses. 
Frictional dissipation forces are indeed much efficient in reducing displacement demands that could be, due to long period isolation systems, subject to long-duration pulses (Makris and Chang 2000). Nevertheless, frictional devices occasionally cause substantial permanent displacements.

To design an anti-seismic device, experimental tests and performance checks are crucial. Overviews of existing testing techniques for dissipative devices for damage in masonry buildings due to OOP can be found in (D'Ayala and Paganoni 2014; Paganoni and D'Ayala 2010). As for the strengthening of masonry structures (Paganoni and D'Ayala 2014), also for the improvement of the dissipative behavior, tests are necessary to define the design process. Therefore, beside the description of the theoretical functioning principle of the LCIORD, this work also presents the results of an experimental campaign performed on free-standing rocking walls at first, and secondly on walls restrained by LICORD. The results are described and interpreted to contribute to the topic of the DAD increasing the knowledge about the energy dissipated during motion in both conditions. Indeed, a challenging issue, still open in the research, is the proper definition of the coefficient of restitution, which measures the amount of dissipated energy during the impacts of the rocking wall on the ground. This parameter strongly influences the dynamic response of rocking walls, as extensively reported in the literature (Giresini et al. 2019a). Unfortunately, only a few experimental tests are available and almost all of them refer to free-standing rocking walls or stone blocks (Sorrentino et al. 2011; Costa et al. 2013; Liberatore et al. 2002; Aslam et al. 1980; Lipscombe and Pellegrino 1993; Peña et al. 2007). Experimental tests were performed to identify the values of coefficients of restitution for different unreinforced masonry specimens of different slenderness and material: marble blocks on marble foundation (Liberatore et al. 2002), concrete blocks with aluminum base on steel foundation (Aslam et al. 1980), steel blocks on steel foundation (Lipscombe and Pellegrino 1993). As for stone/masonry elements, solid clay brick or tuff specimens, with height to thickness ratios between 6.5 and 14.6, were tested in (Sorrentino et al. 2011). The authors found values of the restitution coefficient equal to $95 \%$ of the analytical value. It is self-evident that, in all the tests, the interface material strongly influences the dissipation in free rocking: the greatest energy dissipation was observed to occur on rubber bases, followed by concrete and timber bases (Dolce et al. 2007). At the authors' knowledge, only one set of rocking tests was performed in situ for over one century-old rubble masonry walls restrained by equivalent tie-rods (Giresini et al. 2018a). The need of being aware of the actual value of the coefficient of restitution to assume in analytical models is compelling for making these analyses sufficiently reliable. Generally, in the cited works, the test results are elaborated considering velocity or displacement time histories and calculating the analytical values of coefficient of restitution as ratio of velocity before and after the impact (Housner 1963). The experimental tests were addressed to properly correct this analytical parameter correlated to the block slenderness (Housner 1963; Makris and Konstantinidis 2003).

The actual restitution coefficient is generally lower than the analytical one, due to geometrical imperfections or local plastic deformations that cause energy dissipation, but sometimes it was found to be greater as it will be discussed in 0. For masonry specimens of clay brick (Sorrentino et al. 2011) and rubble masonry with historic mortar (Giresini et al. 2018a), the ratio of experimental coefficient of restitution to analytical coefficient of restitution was found to be between 80 and 95\%, with lower values (about 80\%) referring to walls restrained by equivalent tie-rods, and from 85 to $95 \%$ for free-standing walls. This work widens the knowledge about the coefficient of restitution as key parameter in the rocking analysis, which also reveals to be a significant parameter able to measure the energy dissipated for the free-standing wall and for wall restrained by LICORD, whose 
description is provided in Sect. 2. By analyzing the results of the experimental campaign, presented in Sect. 3, the experimental evidences about the energy dissipated during rocking are discussed in Sect. 4. In the same section, the effectiveness of LICORD is discussed through the comparison of the dynamic responses between the free-standing walls and the restrained walls.

\section{Licord: an innovative anti-seismic device to control oop of masonry walls}

LInear COntrolled Rocking Device (LICORD) is an innovative anti-seismic device able to reduce the vulnerability of existing masonry buildings improving their out-of-plane behavior. The device, covered by patent n. 1,020,180,000,004,026 (inventor: first author of this paper, title translated from Italian: LICORD device for the retrofitting and seismic protection of masonry buildings, date of filing 2018-03-28), is composed by one (Fig. 1a) or multiple shock absorbers (Fig. 1b) and springs coaxial or in parallel with the central steel tie-rod. In case of multiple shock absorbers, they are located at the three vertices of an equilateral triangle (Fig. 1b). The device is conceived to be coupled to a traditional anti-seismic device (a steel tie-rod or catena) which is only able to counteract out-of-plane actions only through its own elasticity. With the addition of LICORD, the horizontal restraint dissipates energy and re-centers the wall at its rest position by means of a spring much more flexible than the tie-rod itself.

The tie-rod is connected to an external plate, to which an internal cylinder is welded. This cylinder is in turn connected to another cylinder through shear pins. The internal cylinder is welded to a plate united with the wall by means of strength anchors. The shock absorber is located inside the steel cylinders, which can be also squared in shape.

The design of LICORD is performance-based: up to a serviceability limit, namely at low levels of seismic action, only the tie-rod counteracts the out-of-plane movement of the wall. At this stage, the internal and external plate are connected by the shear pins. Once that a threshold value of seismic input is attained, the shear pins break, the cylinders slide past each other and LICORD is activated. LICORD completely bypasses the tie-rod elasticity due to its own stiffness, of one or two orders of magnitude lower than that of the tie-rod. This device consists in combining traditional restrain techniques such as steel tierods, frequently used in historic buildings during the last centuries, with an individual or multiple shock absorbers coupled to a re-centering system. When the out-of-plane motion

(a)

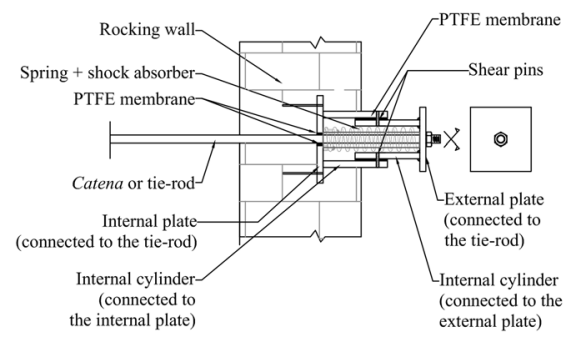

(b)

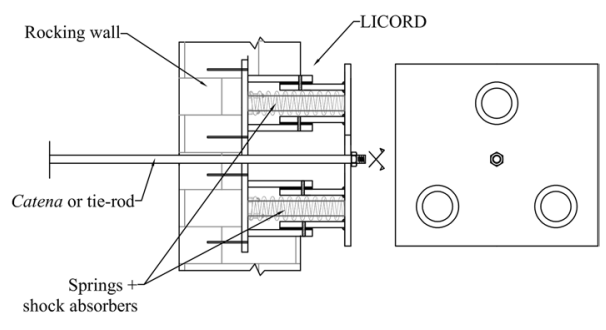

Fig. 1 LICORD in the base configuration (one device) (a) and with multiple shock absorbers (b) 
of a façade is activated, LICORD, based on the Damage Avoidance Design (DAD) philosophy, dampens the wall by controlling its rocking motion and limiting the rebound effects on adjacent walls and the tie-rod failure.

The analytical model of the rigid block can generally include the presence of transversal walls, horizontal diaphragm, additional thrust $H_{f}$ and mass $m_{f}$, with certain eccentricity (Fig. 2). A diaphragm (floor or roof) can be represented by a single horizontal spring of stiffness $K_{f}$, whereas the transverse walls can be modelled as spring bed of stiffness $K_{c}$ predominantly acting in compression. A similar model has been analyzed in (Giresini et al. 2016). In this work the attention is focused on the influence of the anti-seismic device on the bilateral motion of masonry walls, hence the presence of transversal walls and horizontal diaphragms is neglected. Let the rocking wall be connected to a steel tie-rod and to LICORD. LICORD is schematically defined by a shock absorber of equivalent viscous coefficient $c_{L I C}$ and a spring of elastic coefficient $K_{\text {LIC }}$ (Fig. 2). The tie-rod, of stiffness $K_{t i e}$, is only connected to the LICORD external plate, whilst LICORD is connected to the external plate and the internal plate, in turn united with the rocking wall. The system has two degrees of freedom: the rotation $\vartheta$ of the rocking block and the displacement of the LICORD external plate $u_{p}$ (Fig. 2). An equivalent system can be defined through an equivalent stiffness $K_{e q}$ considering two equivalent springs in series.

As for the use of LICORD in real buildings, some observations are needed. The LICORD device follows the innovative concepts of damage avoidance design, therefore it cannot be included in standards nowadays available. Specific limit states in terms of normalized rotation of the rocking wall have to be provided. The damages of the connected elements (shear pins, steel tie-rod, masonry adjacent to LICORD) have to be verified before the LICORD design. This procedure is aimed at guaranteeing a hierarchy of strength between structural elements to ensure that the mechanism will take place without any localized damage. If a damage on these elements is detected at the design phase, proper retrofitting solutions (e.g. localized strengthening) will be defined. In line of principle, LICORD can control the OOP modes of different mechanisms such as simple overturning, horizontal and vertical bending, corner mechanism, etc. The type of mechanism that LICORD can control depends on the position of the tie-rod, since LICORD constitutes the extremity of it. Modes of failure of walls pinned or clamped at the floor level cannot be
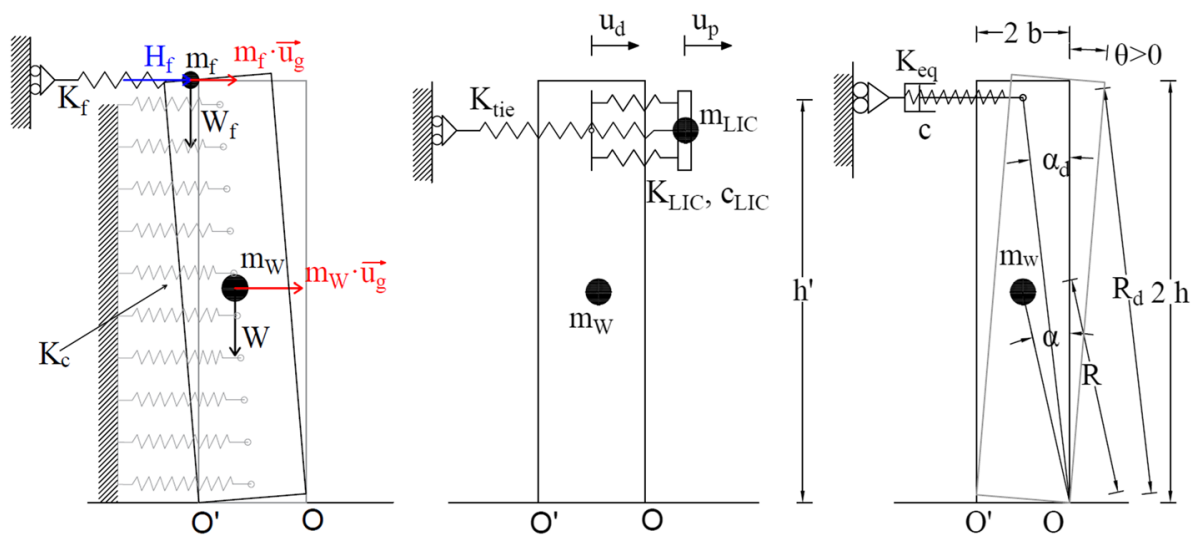

Fig. 2 Analytical model of a rocking wall or rigid block interacting with transversal walls and horizontal diaphragms, connected to LICORD and the corresponding 2DOF system 
taken into account, due to the assumption of base rocking. Therefore, a failure mode identification (Novelli and D'Ayala 2019; Giordano et al. 2020) must verify that these modes can be excluded or play a minor role in the vulnerability assessment.

The number of LICORD devices in masonry buildings can vary considering the mass to be dampened. In general, one can assume to adopt LICORD at the extremities of the tierod. The corresponding damping effect can be adjusted by modifying the indentation/click of the shock absorbers. A preliminary design could include:

- Force-based approaches for the serviceability limit state, which defines the inactive condition of LICORD and ends at the failure of the shear pins;

- Displacement-based approaches through kinematic and/or non-linear dynamic analysis.

An important issue referring to the design of LICORD consists in finding reliable demands in terms of intensity measures. As in rocking analysis the peak ground velocity is a relevant intensity measure, one could assume to preliminarily design LICORD by considering as hazard parameter the peak ground velocity at the site of the building. From it, the kinetic energy to be absorbed-function of the wall mass and of the demand velocity-gives an estimation of the equivalent damping ratio that LICORD has to guarantee. Since, as it will be shown, walls with LICORD imply a greater dissipation of energy than walls without it, LICORD has a beneficial effect for the reduction of the demand hazard parameter in terms of velocity. Moreover, it reduces oscillation amplitudes and stabilizes the frequency content of the dynamic response.

Finally, it is observed that two LICORD devices at the extremities of a single tie-rod could bring to in-phase or counter-phase behavior of the parallel walls connected by the steel tie-rod. This relevant aspect has to be considered prior the design of LICORD and will be discussed in future works.

\section{Experimental campaign on rocking masonry walls}

\subsection{Mechanical characterization of single components and of assembled LICORD}

LICORD was tested in the laboratory of the company LIVITH SPA (Montespertoli, Florence, Italy), to analyze the mechanical parameters influencing its dynamic response. Firstly, the single components of LICORD (springs and shock absorbers) are tested. Secondly, the whole assemblage of LICORD is mechanically characterized on a test bench.

In the first phase, the spring, coaxial to the tie-rod, and the shock absorbers of the prototype shown in Fig. 1b are characterized. In particular, the stiffness of the spring (Fig. 3c) and the equivalent damping coefficient of the shock absorbers (Fig. 3b) are measured before assembling them in the LICORD prototype (Fig. 3d).

\subsubsection{Springs and shock absorbers}

The stiffness of a single coil spring (length $200 \mathrm{~mm}$, diameter $50 \mathrm{~mm}$ ) is measured by tensile-compression tests, obtaining the average value of $18 \mathrm{~N} / \mathrm{mm}$. The shock absorbers are OHLINS mod. GG1487, with length of $465 \mathrm{~mm}$ and piston stroke of $120 \mathrm{~mm}$.

The shock absorbers have valves which can be adjusted by means of an allen screw with 21 indentations/clicks (from T1 to T21). A closed valve slows down the extension 
(a)

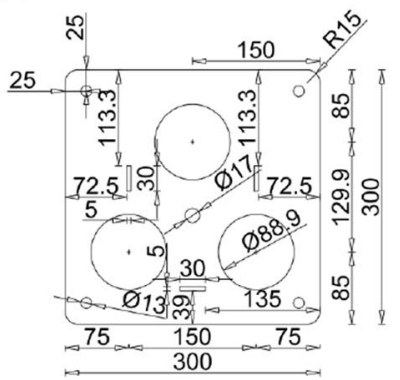

$\varnothing_{\mathrm{EXT}}=88,9 \mathrm{~mm} ; \mathrm{s}=5 \mathrm{~mm} ; \mathrm{L}=310 \mathrm{~mm}$ 78.9 88.9

(d)

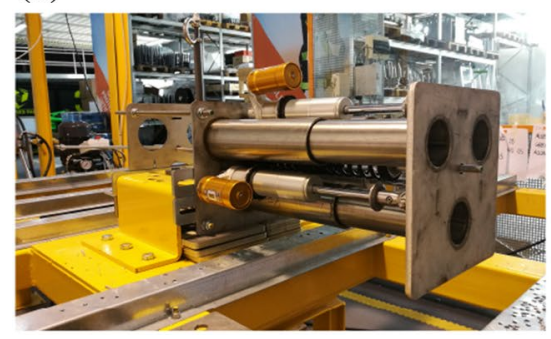

(b)

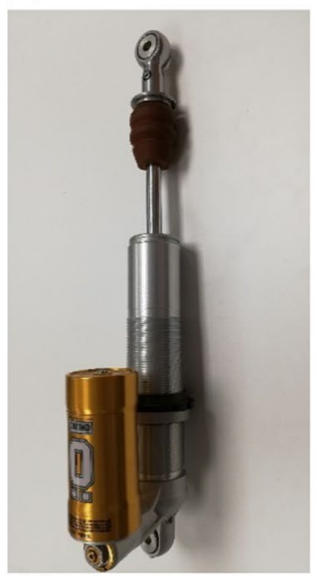

(c)

(e)

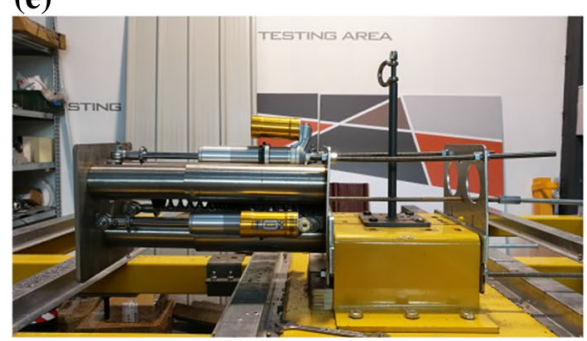

Fig. 3 Measures in mm of the tested LICORD components (a) and test on LICORD (d, e) composed by three shock absorbers $(\mathbf{b})$ and one spring $(\mathbf{c})$

and the compression increasing both time and resistance of the hydraulic piston. From T1 (fully open valve or minimum piston resistance) to T21 (closed valve or maximum piston resistance), the equivalent damping coefficient increases. The label T0, used in the following, means zero damping (LICORD not installed, or free wall). The shock absorbers are individually tested in extension and compression by applying different loading speeds. The corresponding load-position and load-velocity curves are respectively reported in Fig. 4a and $\mathrm{b}$. Each curve, labelled with $\mathrm{Ti}(\mathrm{i}=1,7,14,21)$, is composed by 503 points defined by as many pairs of force-displacement values. These curves are elaborated to obtain the equivalent damping coefficients through the following procedure:

1. Fixed $\mathrm{Ti}, \mathrm{c}_{1}$ is calculated as ratio of force to velocity for each pair, only considering absolute values of velocity greater than $100 \mathrm{~mm} / \mathrm{s}$;

2. Sets of $\mathrm{c}_{\text {comp }}-\mathrm{c}_{\mathrm{ext}}$ are obtained for each phase of compression and extension of the shock absorbers;

3. The arithmetic average values of $\mathrm{c}_{\mathrm{comp}}-\mathrm{c}_{\mathrm{ext}}$ are calculated in each phase and reported in Table 1 together with the corresponding arithmetic average of velocity and standard deviation $\sigma$.

The relationship between the degree of valve opening and the equivalent damping coefficients is not linear: one can observe that the value of $\mathrm{c}_{1}$ is halved from T21 to T1; 
(a)

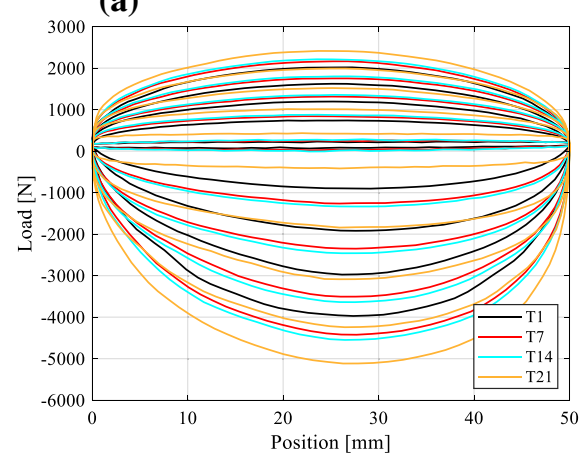

(b)

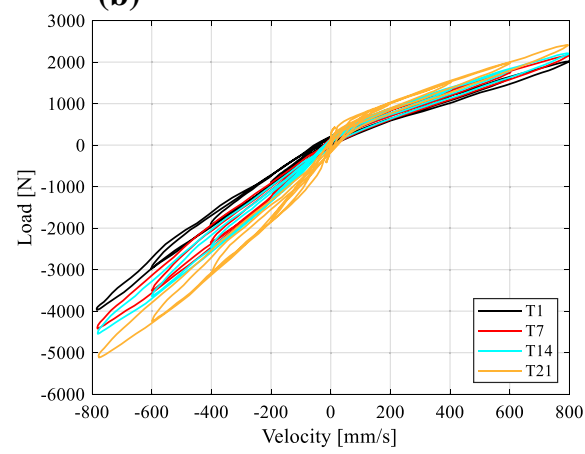

Fig. 4 Response plots of the shock absorbers on test bench: load-position (a) and load-velocity (b) curves

however, from T7 to T14 there is not much difference. The minimum standard deviation is seen for the piston with minimum resistance (T1). Moreover, the values in compression are about half of those in extension (in bold in Table 1) and this is valid for all the velocity ranges, from about $150 \mathrm{~mm} / \mathrm{s}$ to $550 \mathrm{~mm} / \mathrm{s}$. These velocity ranges are chosen as reference as they correspond to ground velocities for medium-high intensity earthquakes (Ancheta et al. 2013).

\subsubsection{LICORD assemblage}

The LICORD assemblage is composed by one spring, three shock absorbers and three steel cylinders to avoid misalignments. Their dimensions are displayed in Fig. 3a. LICORD is compressed on test bench by applying a tensile force to a steel tie rod and then released through a snap shackle, manually activated. The displacements are firstly measured with a laser measuring device with sampling rate of $4 \mathrm{~Hz}$, after with linear variable differential transducers with sampling rate of $20 \mathrm{~Hz}$. The forces are measured through a load cell with sampling rate of $20 \mathrm{~Hz}$. The testing procedure is as follows:

1. Application of tensile force on a $10 \mathrm{~mm}$ diameter tie-rod (on the right in Fig. 3e) up to about $350 \mathrm{daN}$. This causes the approaching of the moving left plate to the fixed right plate (Fig. 3e), by compressing the central spring and the three shock absorbers;

2. Settling time for possible displacements due to viscous phenomena, causing loss of pre-stress;

3. Measure of the initial displacement $u_{H}$ and of the applied force $F_{H}$ before the release;

4. Release of the device by means of a snap shackle;

5. Continuous measure of forces-displacements in the return phase over time $t$.

The horizontal displacement $u_{H}$ in the return phase is combined with time $t$ and applied force $F_{H}$. The stiffness is calculated from the ratio of $F_{H} / u_{H}$.

The results of this set of tests, performed once for each indentation, are reported in Table 2: the LICORD's stiffness does not sensitively change depending on the indentation, being between 30 and $37 \mathrm{~N} / \mathrm{mm}$ (mean $33.9 \mathrm{~N} / \mathrm{mm}$ and standard deviation $3.1 \mathrm{~N} /$ $\mathrm{mm})$. 


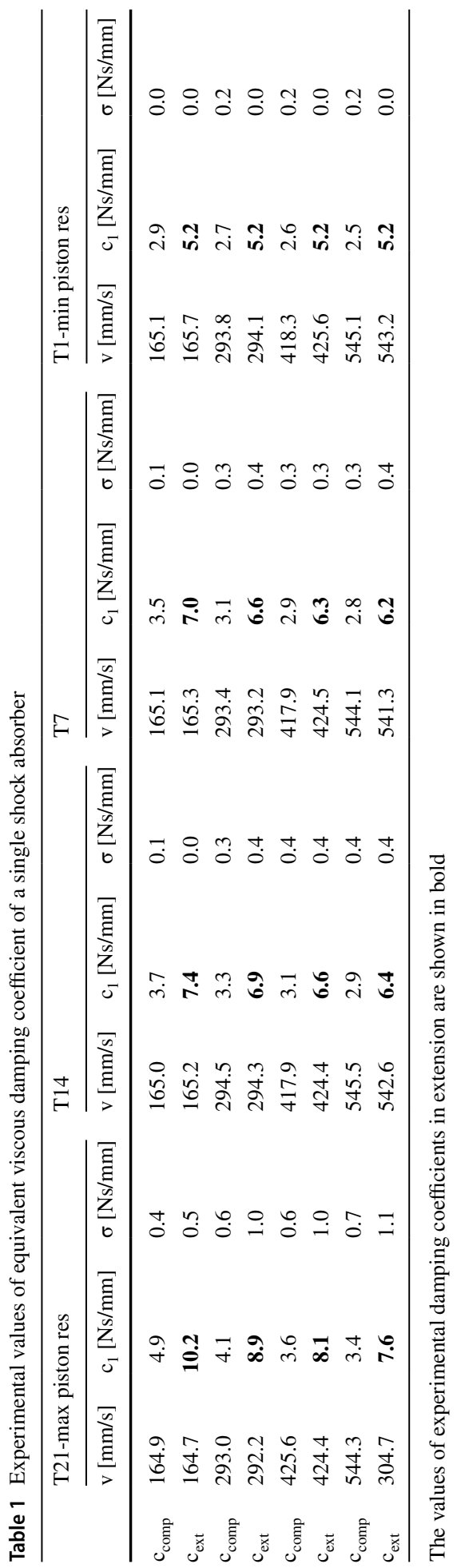


Table 2 Experimental values of LICORD stiffness

\begin{tabular}{llll}
\hline $\mathrm{T} 1$ & $\mathrm{~T} 7$ & $\mathrm{~T} 14$ & $\mathrm{~T} 21$ \\
\hline$F_{H}[\mathrm{~N}]$ & & & \\
3226 & 4077 & 4012 & 3577 \\
$K_{L I C}[\mathrm{~N} / \mathrm{mm}]$ & & & \\
29.33 & 37.1 & 36.5 & 32.5 \\
\hline
\end{tabular}

\subsection{General test set-up}

In total, 43 tests are performed on two walls, labelled A (18 tests) and B (25 tests), made by clay brick and cementitious mortar of slenderness (height/thickness) of respectively 7.5 and 10.8 (Fig. 5). The dimensions are such that these walls are representative of typical one-storey walls in masonry buildings. Table 3 displays the geometric characteristics of the walls, on which two vertical steel strips of dimensions $2700 \times 10 \times 8 \mathrm{~mm}^{3}$ (length $\mathrm{x}$ width $\mathrm{x}$ thickness) are bolted with the aim of forcing the formation of the horizontal hinge at their base (Fig. 6). Details about the mechanical features of the walls and their components can be found in (Giresini et al. 2020).

Two additional walls, thicker but made of hollow clay brick, are built as reaction structure realized by strengthening them with a steel bracing system (walls C-D in Fig. 7). That is the reaction structure when wall $\mathrm{B}$ is tested, whilst when considering wall A another reaction structure, a steel scaffolding, is built on the right side of it.

(a)

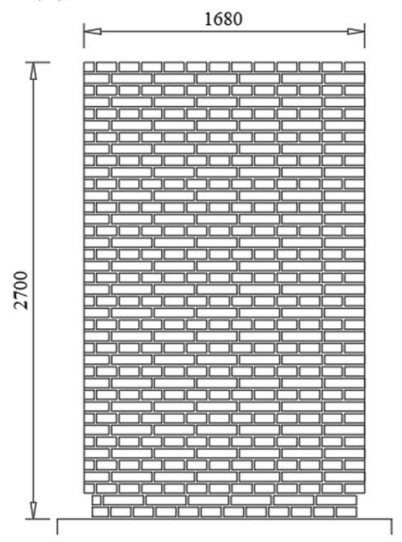

(b)

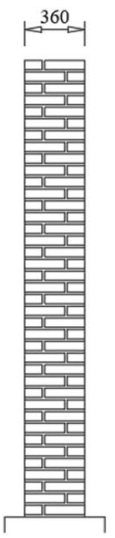

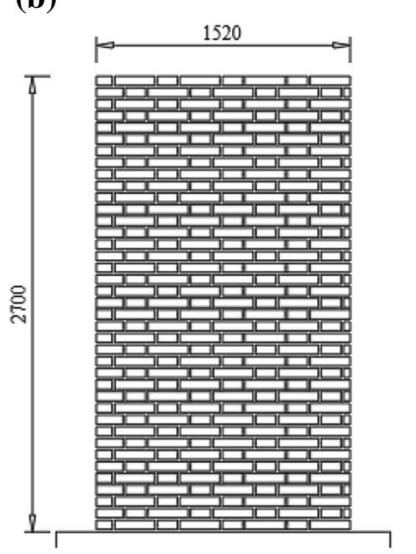

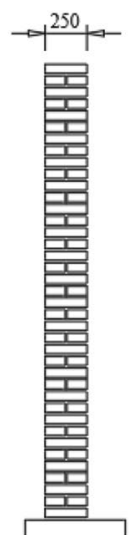

Fig. 5 Wall A (a) and B (b) (units in mm)

Table 3 Geometric characteristics of the walls tested

\begin{tabular}{llllllll}
\hline Wall & Radius vector [m] & $\begin{array}{l}\text { Slender- } \\
\text { ness ratio } \\
{[\mathrm{rad}]}\end{array}$ & Height [m] & Thickness [m] & Width [m] & Weight [kN] Mass [tons] \\
\hline A & 1.362 & 0.133 & 2.7 & 0.36 & 1.68 & 29.39 & 2.9 \\
B & 1.356 & 0.093 & 2.7 & 0.25 & 1.52 & 18.47 & 1.8 \\
\hline
\end{tabular}


(a)

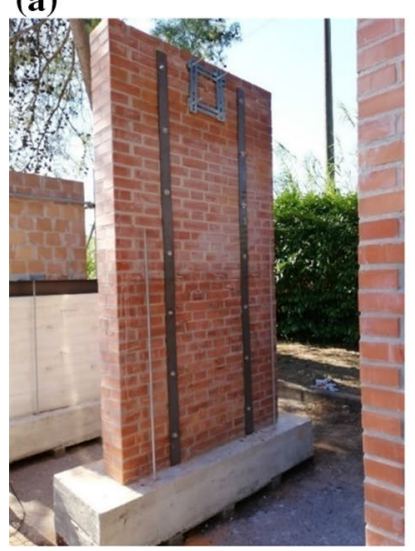

(b)

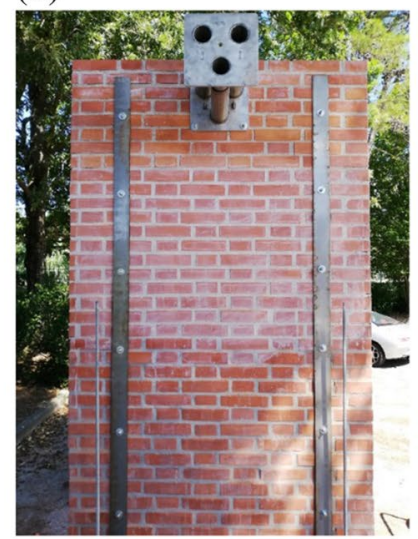

(c)

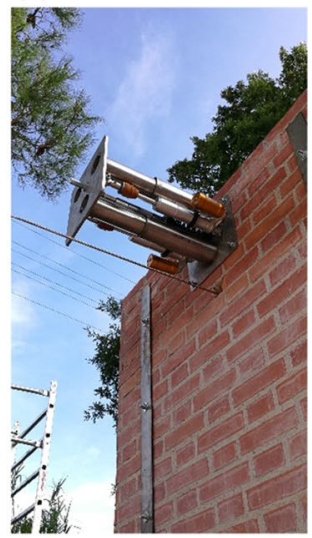

Fig. 6 Wall B, back (a) and front (b) view; wall equipped with LICORD (c)

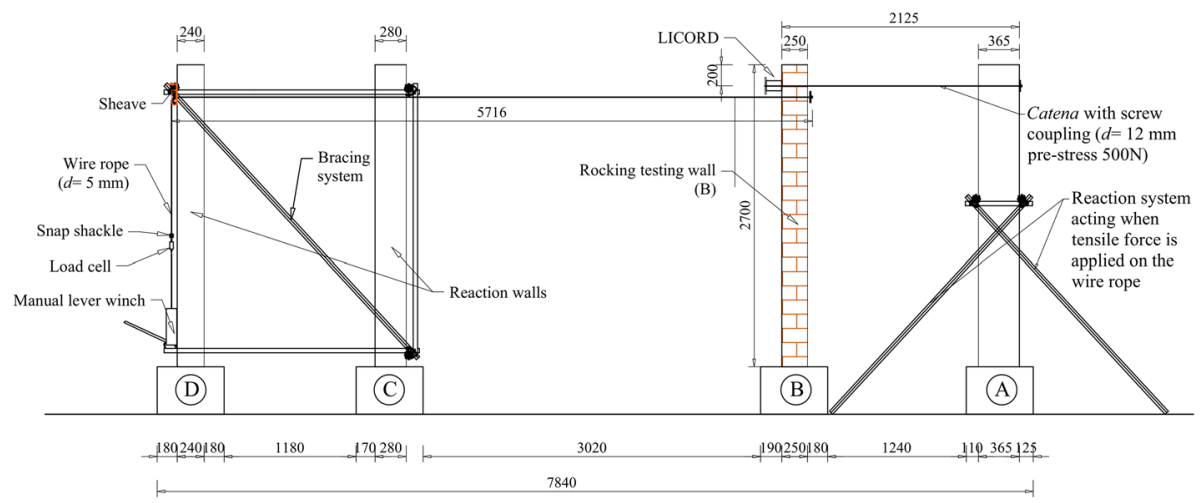

Fig. 7 General test setup for wall B (units in $\mathrm{mm}$ )

The walls are tested in two configurations: (i) free or unrestrained wall (FREE); (ii) wall restrained by a $12 \mathrm{~mm}$ diameter steel tie-rod (or catena) + LICORD (T + number identifying the indentation/click of the shock absorber according to Sect. 3). The first configuration is representative of parapets, altars, statues, artistic assets, whereas the second one simulates walls restrained by steel tie-rods and the here presented anti-seismic device at the top of the wall (Fig. 6). The tests consist in pulling out-of-plane the wall (B in Fig. 7) through a $5 \mathrm{~mm}$ diameter tie put in tension by a manually operated lever winch (on the left of Fig. 7, at height of $2310 \mathrm{~mm}$ from the base of the panel). Once the desired rotation is attained, a snap shackle acts as a quick release system that frees the wall allowing it to rock. The force just before the release is measured through a load cell installed between the snap shackle and the manual lever winch (capacity 2 tons).

Among the 43 performed tests, 25 have been successful; the remaining ones have been discarded due to equipment malfunction and human errors in the uptake of results. The identification label and features of the considered tests are listed in Table 4. The name of each test is such that the first letter indicates the wall, the second the click of the shock absorber which modifies its damping, and finally the progressive number of the test on the 
Table 4 Summary of the tests performed on walls A and B (s.a.=shock absorber)

\begin{tabular}{llllllllll}
\hline Test name & LICORD & Wall & $\begin{array}{l}\text { Click of } \\
\text { s.a }\end{array}$ & $\begin{array}{l}\text { Seq. } \\
\text { number }\end{array}$ & Test name & LICORD & Wall & $\begin{array}{l}\text { Click of } \\
\text { s.a }\end{array}$ & $\begin{array}{l}\text { Seq. } \\
\text { number }\end{array}$ \\
\hline A_T0_1 & $\times$ & A & - & 1 & B_T0_9 & $\times$ & B & - & 9 \\
A_T0_2 & $\times$ & A & - & 2 & B_T0_10 & $\times$ & B & - & 10 \\
A_T0_3 & $\times$ & A & - & 3 & A_T1_1 & $\checkmark$ & A & 1 & 1 \\
A_T0_4 & $\times$ & A & - & 4 & A_T7_1 & $\checkmark$ & A & 7 & 1 \\
A_T0_5 & $\times$ & A & - & 5 & A_T14_1 & $\checkmark$ & A & 14 & 1 \\
B_T0_1 & $\times$ & B & - & 1 & A_T21_1 & $\checkmark$ & A & 21 & 1 \\
B_T0_2 & $\times$ & B & - & 2 & B_T1_1 & $\checkmark$ & B & 1 & 1 \\
B_T0_3 & $\times$ & B & - & 3 & B_T1_2 & $\checkmark$ & B & 1 & 2 \\
B_T0_4 & $\times$ & B & - & 4 & B_T14_1 & $\checkmark$ & B & 14 & 1 \\
B_T0_5 & $\times$ & B & - & 5 & B_T14_2 & $\checkmark$ & B & 14 & 2 \\
B_T0_6 & $\times$ & B & - & 6 & B_T21_1 & $\checkmark$ & B & 21 & 1 \\
B_T0_7 & $\times$ & B & - & 7 & B_T21_2 & $\checkmark$ & B & 21 & 2 \\
B_T0_8 & $\times$ & B & - & 8 & & & & & \\
\hline
\end{tabular}

same specimen. For example, B_T7_2 indicates the second consecutive test on wall B with LICORD having shock absorbers with click T7.

When the wall rotates counterclockwise, its motion is contrasted by the tension of a prestressed $\left(P_{0}=500 \mathrm{~N}\right) 12 \mathrm{~mm}$ diameter tie-rod that simulates the steel tie-rods (or catene) historically used as anti-seismic devices. This tie-rod is installed only in combination with LICORD; instead, it is absent in configuration (i). When the panel rocks in configuration (ii), LICORD is activated and dampens the out-of-plane motion reducing and controlling rocking. LICORD is composed by an inner spring (in series with the tie-rod) whose axial stiffness is sensitively lower than that of the tie-rod (on the right of Fig. 7) in such a way that, when rocking starts, the LICORD's stiffness bypasses that of the steel-tie rod re-centering the system. Moreover, LICORD dissipates energy with the damping of the internal viscous shock absorbers. It is worthy to observe that the prototype used for the experimental tests is unwieldly for practical purposes. Indeed, its dimensions are due to the used shock absorbers, which are rather bulky (Fig. 3). As observed in (Melatti et al. 2019), heritage conservation principles regulated in international guidelines suggest that the benefit of the seismic device must compensate for the impact on the original aesthetic of the building. To reduce this impact, a process of optimization of size and dimensions has brought to the realization of a compact prototype with exactly the same operating principles and with a square external plate with side of $250 \mathrm{~mm}$ and piston stroke of $100 \mathrm{~mm}$. Moreover, the installation condition will be semi-embedded or fully embedded in the masonry wall. In this case, LICORD can be successfully used also for historic buildings where the aesthetical impact is a relevant issue.

\subsection{Data acquisition}

During the experimental tests performed on the walls, forces, acceleration and displacement time histories are recorded. In particular, the accelerations in the three directions and horizontal displacements are monitored by means of two accelerometers (TROMINO, model MOHO) and two potentiometric displacement transducers (GEFRAN model 
PZ-34), a laser measuring device (LOKE model LMC-J-0040) and a load cell (AEP model TSA, capacity 2 tons) positioned as displayed in Fig. 8. The positioning of sensors at different heights allows to exclude possible sliding phenomena at the base of the panel, whilst bending of masonry can be reliably neglected due to the presence of the steel plates along the wall height.

\subsection{Dynamic tests}

The dynamic tests are performed by pulling the wall out-of-plane imposing an initial displacement and then releasing the wall as described in $\S 0$. A total of 25 tests is performed considering different damping values by changing the click of the shock absorbers (Table 4). The imposed horizontal displacement in the measure points of wall A (at $2.5 \mathrm{~m}$ from the base) and wall $\mathrm{B}$ (at $2.6 \mathrm{~m}$ ) is equal to $100 \mathrm{~mm}$. The maximum theoretical horizontal displacement is slightly greater than $100 \mathrm{~mm}$ due to the fact the piston rod stroke of LVDTs is $200 \mathrm{~mm}$. Displacement time histories (DTH) and acceleration time histories (ATH) are registered by sensors installed as shown in Fig. 8. The velocity time histories (VTH), used in the following to gather the coefficients of restitution, are obtained through derivation of DTH. A cross-check with the integration of ATH is finally performed to ensure the absence of sliding phenomena or numerical errors.

\section{Experimental evidences on the energy dissipation}

\subsection{Analysis of displacement time histories and LICORD's effectiveness}

This paragraph discusses the effectiveness of LICORD in the two rocking walls of different slenderness subjected to free vibrations. Three relevant effects are recognized when LICORD restraints the wall:
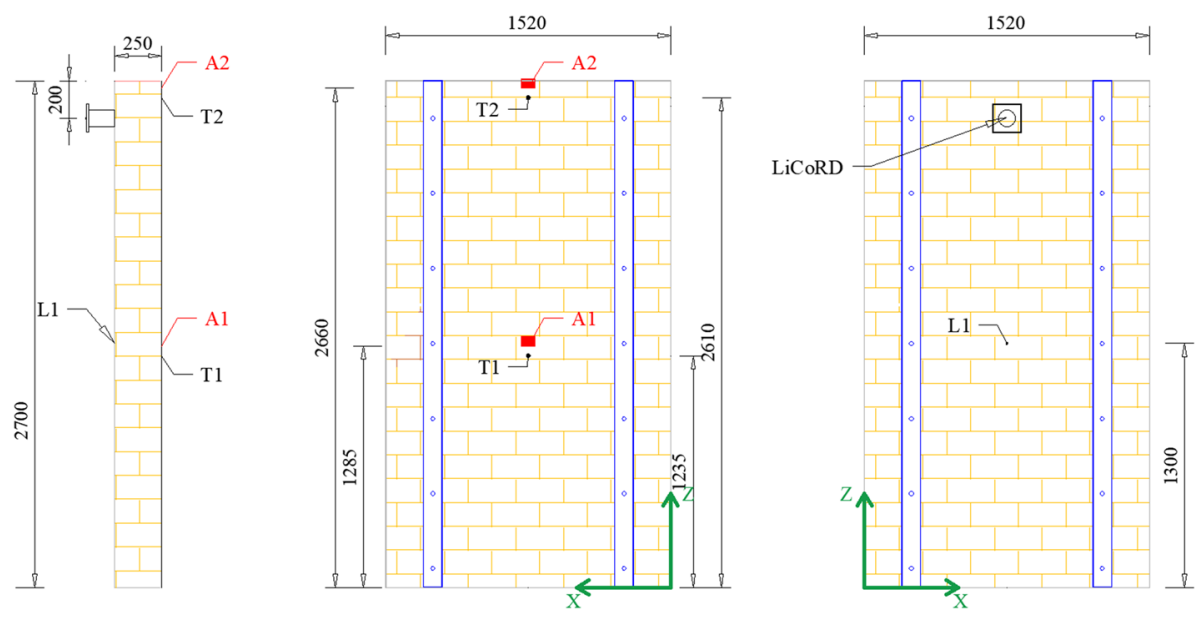

Fig. 8 Position of accelerometers (A), laser measuring device (L) and displacement transducers (T) in wall B. Units in $\mathrm{mm}$ 
(a)

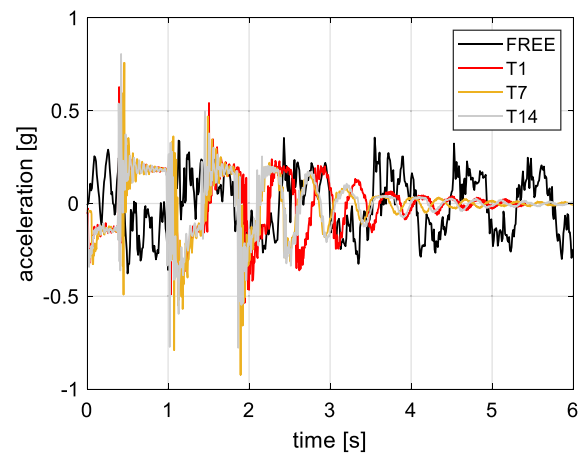

(b)

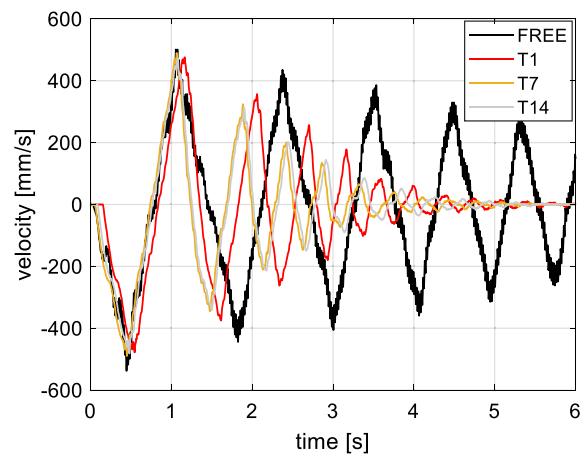

Fig. 9 ATH (a) and VTH (b) of wall A with initial imposed displacement d $=100 \mathrm{~mm}(\mathbf{b})$

(a)

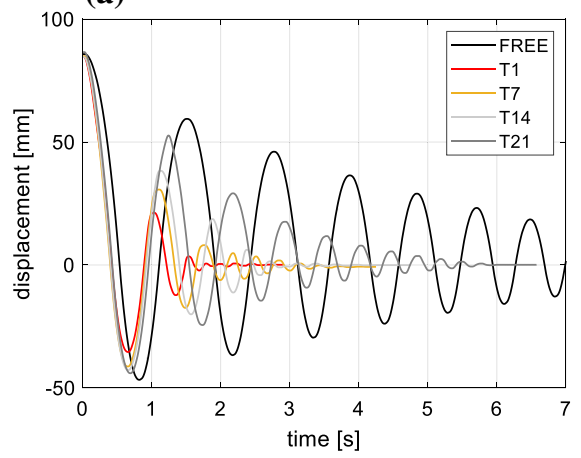

(b)

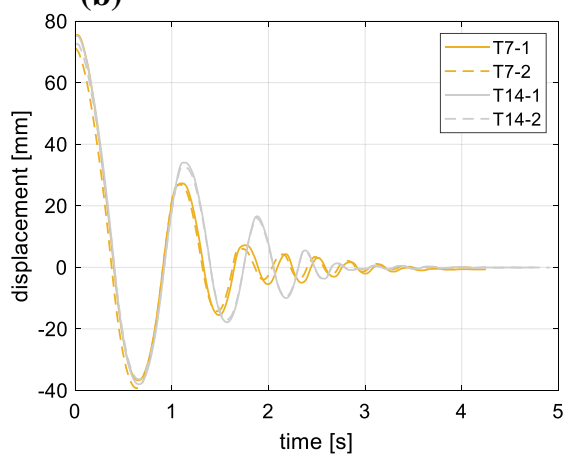

Fig. 10 DTH of wall B: comparison between free and restrained condition (a) and between same specimens tested in sequence (b)

1. Reduction of rotation amplitudes (peak decrement);

2. Reduction of number of impacts;

3. Increase of vibration frequency.

The first two aspects are beneficial, as the requirement of a design limit state (e.g. moderate rocking or limited rocking (Giresini et al. 2019b) can be more likely fulfilled in terms of maximum normalized rotation. Moreover, the reduction of number of impacts, although the motion is here two-sided and therefore not fully realistic, lowers the risk of localized damages on the transverse masonry walls due to pounding of the rocking wall on transverse elements. Indeed, one of the reasons behind the LICORD's conception is to control rocking in that the impacts are limited to avoid damages induced to the adjacent walls and to the tie-rod to which LICORD is connected.

The experimental results are reported in Fig. 9 in terms of acceleration (ATH) and velocity (VTH) time histories. The ATHs are obtained from the accelerometers and they are not subjected to further elaborations, whereas the VTHs are calculated by deriving the displacement time-histories (DTHs), which are provided by the LVDTs and are smooth as displayed in Figs. 10 and 11. 
(a)

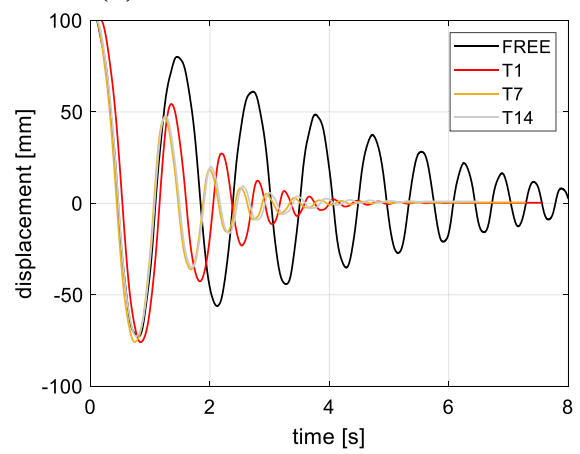

(b)

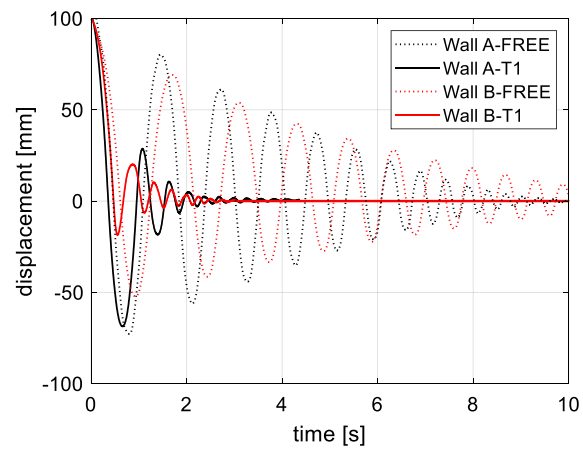

Fig. 11 DTH of wall A with shock absorbers with same damping in extension and compression (a) and DTH of walls A and B with different damping in extension and compression

Firstly, the tests are performed on the slenderer wall (B). By setting the same number of clicks of LICORD in extension and in compression (T1-T7-T14-T21), a meaningful reduction of displacement peaks is observed when LICORD is installed (Fig. 10a). In addition, the number of impacts in the restrained conditions is at least half than the number of impacts when the wall is free to rock. The negligible damage accumulation on the base hinge during each impact is demonstrated by the DTHs trend, an extract of which is shown in Fig. 10b. The DTHs basically do not exhibit variations in the peaks when the same wall with same conditions (same click of the shock absorbers) is tested.

By analyzing the change of response varying the click of the shock absorber, and therefore its damping coefficient, some counterintuitive behaviors can occur. As a matter of fact, LICORD with higher damping can give greater rotation amplitudes as damping increases (T1, T7, T14, T21, Fig. 10a).

This response is easily understandable when considering the boundary conditions of the test. Looking at Fig. 7, LICORD is connected to the tie-rod which has a reaction plate in contact with the reaction wall (which is wall A in Fig. 7 when wall B is tested). When the tie-rod passes from tension to compression state, it becomes an inactive restraint and LICORD does not induce effects to the rocking wall in terms of energy dissipation. Indeed, in this case, the relative velocity between external plate and internal plate of LICORD is near zero. This occurs, for instance, for T21, whose response is similar to that of the free wall: indeed, the damping associated to click T21 makes LICORD too stiff to re-open in short time and hence to become active. The more the piston is soft, the more LICORD is able to compress and therefore capable to efficiently dampen the oscillation. That is why LICORD with T1 dampens more the wall (Fig. 10a).

This behavior does not occur for wall A, for which greater damping (up to T14), corresponds to a significant reduction of peak and number of impacts (Fig. 11a). In any case, to avoid the unexpected behavior described for wall $\mathrm{B}$, a proper tuning of the click in extension and in compression has to be made. After several tests, an optimal solution consisted in setting the rebound click (corresponding to LICORD in extension) at T1 and the clicks in compression from $\mathrm{T} 1$ to $\mathrm{T} 21$. By varying the clicks in compression, the response does not significantly vary. Thus, only the response for $\mathrm{T} 1$ is shown in Fig. 11b. With such an optimized tuning of shock absorber, one obtains a reduction of peak amplitude by $63 \%$ (wall A, from 80 to $30 \mathrm{~mm}$ ) and by $72 \%$ (wall $\mathrm{B}$, from 70 to $20 \mathrm{~mm}$ ) considering the 
second positive peak when LICORD works in compression. Moreover, the vibration frequency shortens for the restrained condition with respect to the free wall; this effect is more evident for the more slender wall (red continuous curve in Fig. 11b). As for the behavior in free condition, wall A dissipates more energy since it is stockier, and therefore considering the Housner's formula of coefficient of restitution, $e$ is lower.

In any case, proper equations of motion, that will be presented by the Authors in future works, will be able to predict, depending on the geometric wall parameters and on the mechanical LICORD parameters, the correct value of $c$ and therefore of $\mathrm{T}$ for which the wall with LICORD is compliant with pre-defined design limit states (Giresini et al. 2018b).

\subsection{Analytical considerations and literature experimental results}

The coefficient of restitution is expressed in the pioneering Housner's work (Housner 1963 ) as square root of kinetic energy ratios before and after impact. It reads:

$$
e_{H}=1-\frac{3}{2} \sin ^{2} \alpha=\frac{2 \mu^{2}-1}{2\left(\mu^{2}+1\right)}
$$

where $\mu=h / b$ is the height to thickness ratio. $e_{H}$ depends upon the slenderness ratio $\alpha$ (Fig. 2) but is independent from the material properties and from the block size: the higher the slenderness, the lower the energy loss for the same input action. This analytical expression is obtained by equating the moment of angular momentum before and after impact of a perpendicular block.

In this work, sufficiently slender blocks are considered (according to Housner (Housner 1963), a block can be defined slender if $\alpha<20^{\circ}$, corresponding to height to thickness ratio $h / s>2.75$ ), so that bouncing or sliding can be neglected. Lipscombe and Pellegrino (Lipscombe and Pellegrino 1993) studied the lower limit of $h / s$ for which bouncing stops within half oscillation cycle in free vibration tests. They found that, for $h / s>2.75$, bouncing can be neglected if the coefficient of restitution is less than 0.8 . For greater slenderness values (up to 5 ), for $e_{H} \leq 0.95$ bouncing can be neglected as well. In this paper, the lower stiffness is that of wall $\mathrm{B}$, for which $\frac{h}{s}=7.5$. Therefore, the hypothesis of bouncing is justifiably excluded. Moreover, sliding is absent during the experimental tests as clearly visible from a visual inspection of the base walls during the tests and due to the cross check of the acceleration time histories measured at different heights (Fig. 8), which ensures a pure rotational motion. Once that pure rocking is assumed, the determination of the coefficient of restitution is of the utmost importance for a correct prediction of the dynamic behavior. Generally, for slenderness typical of masonry/stone specimens, the ratio between experimental and analytical values of coefficient of restitution $e_{\text {exp }} / e_{H}$ is less than 1 . For example, a marble block rocking on a marble foundation delivers an average value of $98 \%$ (Liberatore et al. 2002), whereas tuff and solid clay brick masonry walls of slenderness between 6.5 and 14.6 show values by about $95 \%$ (Sorrentino et al. 2011). In experimental tests performed on granite stones ( $h / s$ varying from 4 to 8 ), subjected to free vibrations, harmonic and random motions, the coefficient of restitution was found to approach the analytical value as $h / s$ increases. As for rubble masonry walls of slenderness 6.5 tested in situ and free to rock, that percentage goes from 81 to $88 \%$ (Giresini et al. 2018a). The same walls, tested with horizontal restraints made of chain and springs assembly which simulate tie-rods, are characterized by coefficient of restitution ratios from 74 to $83 \%$. 
Since the walls under examination have slenderness of 10.8 and 7.5 respectively for wall $\mathrm{A}$ and wall $\mathrm{B}$, the ratios $e_{\text {exp }} / e_{H}$ are expected to be similar to those found in the literature in free condition of vibration. In the next paragraph, the experimental results found for the walls free and restrained by LICORD are discussed.

\subsection{Estimation of coefficients of restitution from the experimental tests}

\subsubsection{General results}

As discussed in (Casapulla et al. 2017; Sorrentino et al. 2011; Giresini et al. 2018a) and in the previous paragraph, the actual coefficient of restitution for masonry walls is usually experimentally lower than the analytical value. The experimental ratio of coefficient of restitution can be found through the following expression (Housner 1963):

$$
\frac{e_{\exp }}{e_{H}}=\frac{v_{i+1}}{v_{i}}
$$

in which $e_{\text {exp }}$ is the experimental value of the coefficient of restitution and $e_{H}$ the anaytical value as in Eq. (1). $v_{i+1}$ is the peak velocity at impact $(i+1)$-th, whilst $v_{i}$ is the velocity at impact i-th. As already pointed out, literature values refer to ratios of $\frac{e_{e x p}}{e_{H}}=85 \%-95 \%$ for free walls (Sorrentino et al. 2011; Giresini et al. 2018a) and of about $80 \%$ for horizontally restrained walls (Giresini et al. 2018a). As visible in Table 5 for free walls (fourth column), the experimental results confirm this trend, exhibiting an average ratio $e_{E x p} / e_{H}$ by about $95 \%$. It should be pointed out that the mentioned literature result $\left(\frac{e_{e x p}}{e_{H}}=85 \%\right)$ refers to $i n$ situ tests performed on historic rubble masonry dated back to 1900 , whereas this campaign is executed on new built clay brick masonry. The in-situ conditions, such as imperfect foundation surface and interference of the rocking wall with the adjacent walls, although cut, undoubtedly imply an increase of energy dissipation as more "equivalent" impacts are likely to occur. In a satisfactory way, the ratio $\frac{e_{\text {exp }}}{e_{H}}$ found in the present tests is closer to the literature results of solid clay brick walls tested in laboratory for two sided rocking, which is precisely $95 \%$ (Sorrentino et al. 2011).

It is interesting to notice that the reduction by $5 \%$ of the coefficient of restitution, found in (Giresini et al. 2018a) passing from free wall to wall restrained only by an elastic element (with no or very low damping) is confirmed also in this case, although the wall characteristics are much different (regular texture vs. rubble masonry and different geometric features). Indeed, the average value of coefficient of restitution for both free walls is $95 \%$, whereas that of the wall $\mathrm{B}$ restrained by LICORD with high damping (B_T21_1 and B_T21_2), the average ratio $e_{\text {exp }} / e_{H}$ is $90 \%$. This shows the low influence of the restraint type on the value of the coefficient of restitution, as long as the restraint has a low impact in the response. As already explained in Sect. 0, the LICORD's indentation T21 (highest damping) results in a behavior similar to that of the free wall, although the response is damped, as the relative displacement between the external plate and the wall is low. As for the stockier wall A, any significant reduction of $e_{\text {exp }} / e_{H}$ is observed, as shown in the time histories of Fig. 11 from T1 to T14. 
Table 5 Mean values of coefficient of restitution obtained from experimental tests $(+=$ impact during counter-clockwise wall rotation,- - = impact during clockwise wall rotation)

\begin{tabular}{llll}
\hline Test\# $\quad e_{\text {exp }} / e_{H}{ }^{+}(\%)$ & $e_{\text {exp }} / e_{H}{ }^{-}(\%)$ & $e_{\text {exp }} / e_{H}(\%)$ & $\begin{array}{l}e_{\text {exp }} / e_{H}(2 \\
\text { impacts }) \\
\end{array}$ \\
& & $(\%)$
\end{tabular}

Free walls

$\begin{array}{lllll}\text { A_T0_1 } & 93 & 93 & 92 & 97 \\ \text { A_T0_2 } & 97 & 97 & 94 & 94 \\ \text { A_T0_3 } & 97 & 97 & 94 & 99 \\ \text { A_T0_4 } & 97 & 98 & 95 & 99 \\ \text { A_T0_5 } & 91 & 92 & 90 & 88\end{array}$

Walls restrained by LICORD

$\begin{array}{lllll}\text { A_T1_1 } & 80 & 82 & 83 & 91 \\ \text { A_T7_1 } & 80 & 80 & 83 & 88 \\ \text { A_T14_1 } & 83 & 83 & 84 & 88 \\ \text { A_T21_1 } & 96 & 97 & 96 & 97\end{array}$

Free walls

B_T0_1 95

$\begin{array}{lll}95 & 95 & 94\end{array}$

B_T0_2 95

$95 \quad 94$

B_T0_3 95

95

$95 \quad 96$

B_T0_4 95

$95 \quad 97$

B_T0_5 95

$95 \quad 97$

B_T0_6 96

9595

B_T0_7 96

$96 \quad 96$

B_T0_8 96

$96 \quad 97$

B_T0_9 96

$96 \quad 96$

B_T0_10 96

96

95

Walls restrained by LICORD

$\begin{array}{lllll}\text { B_T1_1 } & 68 & 70 & 71 & 81 \\ \text { B_T1_2 } & 66 & 66 & 68 & 77 \\ \text { B_T14_1 } & 75 & 75 & 78 & 86 \\ \text { B_T14_2 } & 71 & 75 & 74 & 85 \\ \text { B_T21_1 } & 89 & 88 & 88 & 90 \\ \text { B_T21_2 } & 90 & 90 & 90 & 91\end{array}$

\subsubsection{Alternative expression of coefficient of restitution considering asymmetric rocking behavior}

The dissipation of energy follows a clear trend for the wall free from restraints: the number of oscillations is on average double with respect to that of the restrained wall. Moreover, unrestrained walls are affected by a reduction of consecutive negative and positive peaks of velocity quite similar in absolute value as the motion is two-sided.

Peaks of velocity, both maximum and minimum values, coincide with impacts, where the kinetic energy is maximum. By contrast, in presence of LICORD, the consecutive negative and positive peaks of velocity are strongly different: this suggests that there is a diverse behavior in the two directions of rotation. To analyze such a different behavior, the coefficient of restitution can be obtained by: 


$$
e_{e x p} / e_{H}^{+}=\sqrt{\frac{v_{i+2}^{+}}{v_{i}^{+}}} ; e_{e x p} / e_{H}^{-}=\sqrt{\frac{v_{i+2}^{-}}{v_{i}^{-}}}
$$

where $\frac{v_{i+2}^{+}}{v_{i}^{+}}$is the ratio of two consecutive positive maximum velocities and $\frac{v_{i+2}^{-}}{v_{i}^{-}}$is the ratio of two consecutive minimum velocities. This formula is simply obtained by Eq. (2) considering two consecutive velocity peaks. When Eq. (3) is considered in place of Eq. (2), the trend of the coefficients of restitution is much clearer for the analysis of restrained rocking walls. This happens considering both the values of $e_{\text {exp }}$ at each impact and the average values for all the impacts of the same test. For instance, Fig. 12 displays the results in the T14 configuration. When the consecutive peaks of velocities are considered in the calculation of $e_{\text {exp }} / e_{H}$, one has a "zig-zag" and inconsistent trend (continuous black line). However, this conventional calculation permits to observe that a larger dissipation of energy occurs when the wall impacts the left corner (or, in other words, during a counter-clockwise rotation). This is because the tie-rod is active only when the wall rotates counter-clockwise. By contrast, considering Eq. (3) the trend is still of "zig-zag" type but the coefficients of restitution are similar in the two directions of rotation (dotted and dashed lines of Fig. 12). As for the free rocking walls, the mean coefficients of restitution do not vary considering either consecutive peaks or consecutive peaks of the same sign (second and third column of Table 5). For the stockier wall (A), the coefficient of restitution goes from 88 to $98 \%$,

(a)

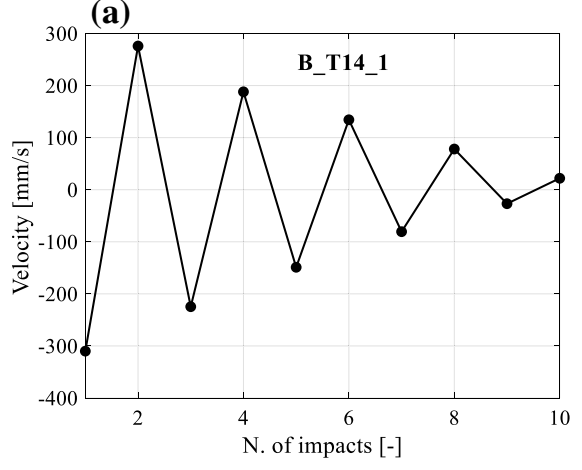

(c)

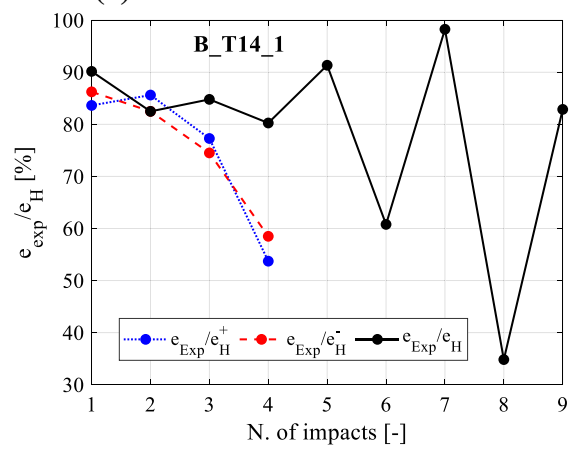

(b)

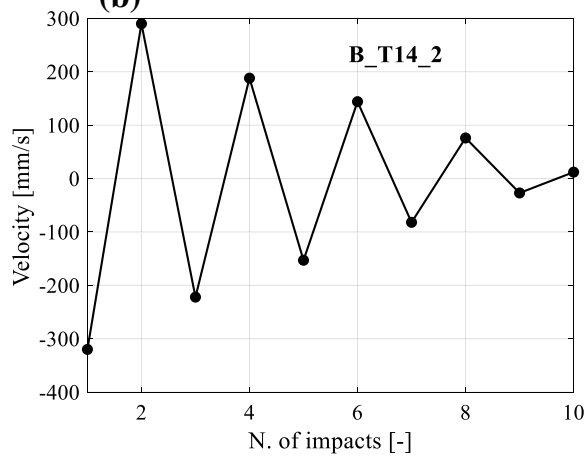

(d)

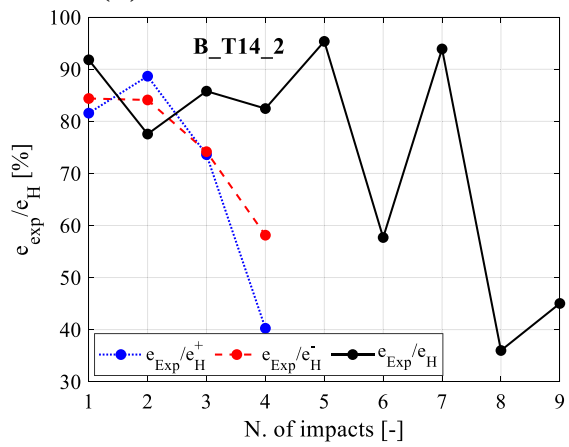

Fig. 12 Velocity peaks (a, b) and coefficients of restitution (c, d) in T14 configuration of wall B (semi-open dissipator) 
whereas for the slender wall (B), the results are less scattered being the minimum $95 \%$ and the maximum $96 \%$. A reference value of $95 \%$ can be considered for both unrestrained walls.

\subsubsection{Investigation on damage accumulation}

The same test repeated with unchanged conditions, that is by applying the same imposed displacement, does not reveal modification of the average energy dissipation. This means that there is not a relevant degradation or a significant modification of the base on which the wall rocks, as demonstrated by the coefficient of restitution values for the same test of variable progressive number (Table 5).

\subsubsection{Remarks about the influence of LICORD's viscous equivalent coefficient on the descoefficient of restitution}

For wall B restrained by LICORD, the more dampened configurations (T1, T14) have mean experimental ratios of respectively $70 \%$ and $75 \%$, highlighting that the additional damping (see Table 1 for the equivalent viscous coefficients of a single shock absorber) clearly increases the dissipated energy of the system. Nevertheless, a greater equivalent viscous coefficient $c$ does not correspond to a greater dissipated energy, quite the reverse. As already pointed out, a fully closed valve (e.g. T21) does not have time enough to open and the relative displacement of LICORD, between the external plate and the internal plate is almost zero; therefore, the wall behaves as it is restrained by the steel tie-rod in counterclockwise rotation and as free in clockwise rotation. By contrast, when the piston resistance is lower, damping can easily occur allowing the two LICORD's plates to properly open and dampen the motion. This controls the rocking oscillation by reducing the number of impacts on the ground and the rotation amplitude. Therefore, it is physically acceptable, as well as desirable, that the equivalent viscous coefficient is not too high. In a further paper, which will present the equations of motion and the comparison between numerical and experimental time histories, an optimal value of $c$ will be defined depending on the walls characteristics. Results for the T7 configuration of wall B have not been reported due to errors in the acquisition of experimental data.

\subsubsection{Variation of energy dissipation depending on the considered number of impacts}

Table 5 also contains in the last column the mean ratios calculated by considering only the first two consecutive impacts: it is evident that a great part of energy is dissipated after the third impact in the walls restrained by LICORD. Instead, for the unrestrained wall there are negligible differences considering all the impacts or the first two impacts on the ground.

Moreover, with a configuration restrained by LICORD, the number of impacts on the ground is significantly lower. This aspect is considered positive since the impacts on the transverse walls is in general detrimental because the impacts can cause local masonry failures.

\subsection{Equivalent viscous damping ratios}

Although the dynamics of rocking blocks clearly differs from the behavior of a SDOF oscillator as described in detail in (Makris and Konstantinidis 2003), a meaningful 
interpretation of results may make use of the logarithmic decrement method (Chopra 2012) to find equivalent damping ratios for unrestrained and restrained rocking walls. The analysis of DTH shows that the equivalent damping ratio passes from 4 (unrestrained wall) to $20 \%$ (wall restrained by LICORD with fully open valve, Table 6). It is worthwhile to notice that, in this case, a higher equivalent viscous coefficient implies a lower energy dissipation since the relative displacement of external and internal LICORD's plates is small, and therefore LICORD is not activated. This reason is the same as that for which the DTH of wall restrained by-say-T21 (fully closed valve), is more similar to that of the wall free to rotate than the less dampened LICORD devices (e.g. Figure 10a). As already pointed out, there exists an optimum value for shock absorbers equivalent viscous coefficient for which LICORD is efficiently activated, optimizing the number of impacts reduction and attenuation of rotation amplitudes.

\section{Conclusions}

This paper investigated the rocking behavior of masonry walls in free vibrations and restrained by an innovative device called LICORD (Linear Controlled Rocking Device). LICORD is made of an individual or multiple shock absorbers and one re-centering element whose stiffness is one-two orders of magnitudes lower than the steel tie-rod to which LICORD is connected. The idea to control rocking is derived by the damage avoidance design concepts and by the need of coupling traditional devices with shock absorbers to dissipate energy. The walls, made of solid clay brick units and cementitious mortar, have slenderness (height to thickness ratio) between 7.5 and 10.8 and are tested considering free vibrations. The first part of the paper presented the mechanical features and operating principles of LICORD, which couples the traditional anti-seismic steel tie-rod, limiting the out of plane modes of masonry walls, to shock absorbers and re-centering systems.

As for the investigation about the coefficient of restitution, it is observed that the ratio experimental/analytical value $\frac{e_{\text {exp }}}{e_{H}}$ found in the present tests for unrestrained walls is on average equal to $95 \%$. This value is satisfactorily almost equal to the literature results found for solid clay brick walls of similar slenderness (about 6.5-10). Moreover, a reduction by $5 \%$ of the coefficient of restitution is observed passing from free wall to wall restrained by LICORD. This confirms analogous tests performed on rubble masonry walls restrained by elastic elements, showing the low influence on restraint type as long as it is elastic (with low damping). Indeed, the average value of coefficient of restitution for the wall restrained by LICORD with high damping is about $90 \%$. An alternative expression for evaluating the coefficient of restitution of restrained walls is proposed to consider the unilateral motion. Indeed, if the traditional expression that considers consecutive peaks is used, one has an

Table 6 Equivalent damping ratios obtained from the logarithmic decrement method (wall $\mathrm{B})\left(\mathrm{c}_{1}\right.$ : equivalent viscous damping coefficient of the single shock absorber in extension for velocity range $100-200 \mathrm{~mm} / \mathrm{s}$ )

\begin{tabular}{lcc}
\hline Level of restraint & $\mathrm{c}_{1}[\mathrm{Ns} / \mathrm{mm}]$ & $\xi_{\text {eq }}$ \\
\hline T0 & 0.0 & $4 \%$ \\
T21 & 10.2 & $7 \%$ \\
T14 & 7.4 & $12 \%$ \\
T7 & 7.0 & $15 \%$ \\
T1 & 5.2 & $20 \%$ \\
\hline
\end{tabular}


inconsistent trend, which stabilizes when the proposed formula is adopted. As for the free rocking walls, the mean coefficients of restitution do not vary considering either consecutive velocity peaks or consecutive peaks of the same sign. Damage accumulation on the base hinge is excluded from the analysis performed on consecutive tests on the same specimens.

Among the beneficial effects induced by LICORD, one can detect (1) reduction of rotation amplitudes (peak decrement); (2) reduction of number of impacts; (3) increase of vibration frequency. Particularly the first two aspects reduce the probability of damage of adjacent structures and tie-rod that could undergo brittle failures. The damping of LICORD can be tuned by modifying the clicks of the shock absorbers in extension and in compression, so to have an optimized response. With the use of LICORD, the maximum reduction of rotation amplitude is by $70 \%$. Considering the logarithmic decrement of the displacement time histories, the equivalent damping ratio passes from 4 (unrestrained wall) to $20 \%$ (wall restrained by LICORD).

The walls tested in this experimental campaign are not connected to transverse walls, as it occurs in real conditions. Shaking table tests are planned to investigate the pushing effect of both unrestrained and restrained walls against transverse walls, to confirm the analytical models. Nevertheless, the campaign described here is considered a necessary step to investigate the behavior of walls free to rock and restrained by LICORD. Further investigations will consider in-phase and counter-phase motions of parallel rocking walls restrained by LICORD, to overcome the limitation imposed by assuming an extremity of the tie-rod as fixed. Finally, the equations of motion of the equivalent two degrees of freedom system (one DOF represented by LICORD and the other one by the wall itself) will be introduced in a specifically developed MATLAB code to design proper applications of LICORD to both monumental and traditional façades of masonry buildings.

Acknowledgements The Authors wish to sincerely acknowledge Dr. Giacomo Di Furia, Eng. Delia D'Arrigo and Eng. Stefano Gaglioti from the company LIVITH SPA (Florence, Italy) for financially supporting the experimental tests and the related research activity. Authors' thank also goes to the TUM (Technische Universität München) University Foundation Fellowship, for supporting the collaboration between the involved universities.

Funding Open access funding provided by Università di Pisa within the CRUI-CARE Agreement.

Open Access This article is licensed under a Creative Commons Attribution 4.0 International License, which permits use, sharing, adaptation, distribution and reproduction in any medium or format, as long as you give appropriate credit to the original author(s) and the source, provide a link to the Creative Commons licence, and indicate if changes were made. The images or other third party material in this article are included in the article's Creative Commons licence, unless indicated otherwise in a credit line to the material. If material is not included in the article's Creative Commons licence and your intended use is not permitted by statutory regulation or exceeds the permitted use, you will need to obtain permission directly from the copyright holder. To view a copy of this licence, visit http://creativecommons.org/licenses/by/4.0/.

\section{References}

Alecci V, Stipo G, La Brusco A, De Stefano M, Rovero L (2019) Estimating elastic modulus of tuff and brick masonry: a comparison between on-site and laboratory tests. Constr Build Mater 204:828-838

Alecci V, De Stefano M, Luciano R, Marra A, Stipo G (2020) Numerical Investigation on the use of flat-jack test for detecting masonry deformability. J Test Eval 49(1):20190781 
Ancheta TD, Darragh RB, Stewart JP, Seyhan E, Silva WJ, Chiou BSJ, Wooddell KE, Graves RW, Kottke AR, Boore DM, Kishida T, Donahue JL (2013) PEER strong motion database record and PEER 2013/03-PEER NGA West2 Database, Pacific Earthquake Engineering Research Center

Argiento LU, Maione A, Giresini L (2019) The corner failure in a masonry building damaged by the 20162017 central Italy earthquake sequence. In: COMPDYN 2019 7th ECCOMAS Thematic Conference on Computational Methods in Structural Dynamics and Earthquake Engineering, Crete; Greece; 24th26th June 2019

Aslam M, Godden WG, Scalise DT (1980) Earthquake rocking response of rigid bodies. J Struct Div 106(2):377-392

Brando G, Rapone D, Spacone E, O’Banion MS, Olsen MJ, Barbosa AR et al (2017) Damage reconnaissance of unreinforced masonry bearing wall buildings after the 2015 Gorkha, Nepal, Earthquake. Earthq Spectra 33(1):243-S273. https://doi.org/10.1193/010817EQS009M

Calderini C, Vecchiattini R, Battini C, Piccardo P (2016) Mechanical and metallographic characterization of iron tie-rods in masonry buildings: An experimental study. In: Proceedings of the 10th International Conference on Structural Analysis of Historical Constructions, SAHC, Leuven, Belgium, September 13-15 2016

Casapulla C, Maione A (2017) Critical response of free-standing rocking blocks to the intense phase of an earthquake. Int Rev Civil Eng 8(1):1

Casapulla C, Jossa P, Maione A (2010) Rocking motion of a masonry rigid block under seismic actions: a new strategy based on the progressive correction of the resonance response. Ingegneria Sismica 27(4):35-48

Casapulla C, Giresini L, Lourenço PB (2017) Rocking and kinematic approaches for rigid block analysis of masonry walls: state of the art and recent developments. Buildings. https://doi.org/10.3390/buildings7 030069

Casapulla C, Giresini L, Argiento LU, Maione A (2019) Nonlinear static and dynamic analysis of rocking masonry corners using rigid macro-block modeling. Int J Struct Stab Dyn 19(11):1950137. https://doi. org/10.1142/S0219455419501372

Chopra AK (2012) Dynamics of structures, Global Edition [Paperback]. 4th ed. Pearson Education. ISBN10: 0273774247; ISBN-13: 9780273774242

Costa AA, Arêde A, Penna A, Costa A (2013) Free rocking response of a regular stone masonry wall with equivalent block approach: experimental and analytical evaluation. Earthq Eng Struct Dynam 42(15):2297-2319. https://doi.org/10.1002/eqe.2327

D'Ayala D (2014) Conservation principles and performance based strengthening of heritage buildings in post-event reconstruction. In: Ansal A (eds) Perspectives on European earthquake engineering and seismology. Geotechnical, Geological and Earthquake Engineering, vol 34. Springer, Cham. https:// doi.org/10.1007/978-3-319-07118-3_15

D'Ayala DF, Paganoni S (2011) Assessment and analysis of damage in L'Aquila historic city centre after 6th April 2009. Bull Earthq Eng 9(1):81-104. https://doi.org/10.1007/s10518-010-9224-4

D'Ayala DF, Paganoni S (2014) Testing and design protocol of dissipative devices for out-of-plane damage. Proc Inst Civil Eng Struct Build 167(1):26-40. https://doi.org/10.1680/stbu.12.00087

Dolce M, Cardone D, Ponzo FC (2007) Shaking-table tests on reinforced concrete frames with different isolation systems. Earthq Eng Struct Dynam 36(5):573-596. https://doi.org/10.1002/eqe.642

Ferreira TM, Costa AA, Costa A (2015) Analysis of the out-of-plane seismic behavior of unreinforced masonry: a literature review. Int J Archit Herit. https://doi.org/10.1080/15583058.2014.885996

Froli M, Giresini L, Laccone F (2019) Dynamics of a new seismic isolation device based on tribological smooth rocking (TROCKSISD). Eng Struct 193:154-169

Froli, M., Giresini, L., Laccone, F.: A new seismic isolation device based on tribological smooth rocking (TRockSISD). In: 7th International Conference on Computational Methods in Structural Dynamics and Earthquake Engineering, COMPDYN 2019, Crete; Greece; 24 June 2019 through 26 June 2019

Giordano N, De Luca F, Sextos A (2020) Out-of-plane closed-form solution for the seismic assessment of unreinforced masonry schools in Nepal. Eng Struct 203:109548. https://doi.org/10.1016/j.engst ruct.2019.109548

Giresini L (2017) Design strategy for the rocking stability of horizontally restrained masonry walls. In: M. Papadrakakis MF, editor. In: COMPDYN 2017 6th ECCOMAS Thematic Conference on Computational Methods in Structural Dynamics and Earthquake Engineering, Rhodes Island, Greece, 15-17 June 2017., Rhodes Island, Greece

Giresini L, Fragiacomo M, Lourenço PB (2015) Comparison between rocking analysis and kinematic analysis for the dynamic out-of-plane behavior of masonry walls. Earthq Eng Struct Dynam 44(13):23592376. https://doi.org/10.1002/eqe.2592 
Giresini L, Fragiacomo M, Sassu M (2016) Rocking analysis of masonry walls interacting with roofs. Eng Struct 116:107-120

Giresini L, Sassu M, Sorrentino L (2018) In situ free-vibration tests on unrestrained and restrained rocking masonry walls. Earthq Eng Struct Dynam 47(15):3006-3025. https://doi.org/10.1002/eqe.3119

Giresini L, Casapulla C, Denysiuk R, Matos J, Sassu M (2018) Fragility curves for free and restrained rocking masonry façades in one-sided motion. Eng Struct 164:195-213. https://doi.org/10.1016/J.ENGST RUCT.2018.03.003

Giresini L, Solarino F, Paganelli O, Oliveira DV, Froli M (2019a) One-sided rocking analysis of corner mechanisms in masonry structures: influence of geometry, energy dissipation, boundary conditions. Soil Dyn Earthq Eng 123:357-370

Giresini L, Taddei F, Casapulla C, Mueller G (2019) Stochastic assessment of rocking masonry façades under real seismic records. In: COMPDYN 2019 7th ECCOMAS Thematic Conference on Computational Methods in Structural Dynamics and Earthquake Engineering, Crete; Greece; 24th-26th June 2019

Giresini L, Puppio ML, Taddei F (2020) Experimental pull-out tests and design indications for strength anchors installed in masonry walls. Mater Struct. https://doi.org/10.1617/s11527-020-01536-2

Griffith MC, Magenes G, Melis G, Picchi L (2003) Evaluation of out-of-plane stability of unreinforced masonry walls subjected to seismic excitation. J Earthq Eng 7:141-169. https://doi.org/10.1080/13632 460309350476

Housner GW (1963) The behavior of inverted pendulum structures during earthquakes. Bull Seismol Soc Am 53(2):403-417. https://doi.org/10.1017/CBO9781107415324.004

Htwe Zaw S, Ornthammarath T, Poovarodom N (2019) Seismic reconnaissance and observed damage after the Mw 6.8, 24 August 2016 Chauk (Central Myanmar) Earthquake. J Earthq Eng 23(2):284-304. https://doi.org/10.1080/13632469.2017.1323050

Lagomarsino S (2015) \{S \} eismic assessment of rocking masonry structures. Bull Earthq Eng 13(1):97-128. https://doi.org/10.1007/s10518-014-9609-x

Liberatore D, Spera G, D’Alessandro G, Nigro, D (2002) Rocking of slender blocks subjected to seismic motion of the base. In: 12th European conference on earthquake engineering, London

Lipscombe PR, Pellegrino S (1993) \{F\}ree rocking of prismatic blocks. J Struct Eng 119(7):1387-1410. https://doi.org/10.1061/(ASCE)0733-9399(1993)119:7(1387)

Makris N, Chang SP (2000) Effect of viscous, viscoplastic and friction damping on the response of seismic isolated structures. Earthq Eng Struct Dynam 29(1):85-107. https://doi.org/10.1002/(SICI)10969845(200001)29:1\%3c85::AID-EQE902\%3e3.0.CO;2-N

Makris N, Konstantinidis D (2003) The rocking spectrum and the limitations of practical design methodologies. Earthq Eng Struct Dynam 32(2):265-289. https://doi.org/10.1002/eqe.223

Melatti V, D'Ayala D, Modolo E (2019) Computational validation of dissipative device for the seismic upgrade of historic buildings. In: COMPDYN 2019 7th ECCOMAS Thematic Conference on Computational Methods in Structural Dynamics and Earthquake Engineering, Crete; Greece; 24th-26th June 2019: 2019. https://doi.org/10.7712/120119.7293.19538.

Novelli VI, D'Ayala D (2019) Use of the knowledge-based system LOG-IDEAH to assess failure modes of masonry buildings, damaged by L'Aquila earthquake in 2009. Front Built Environ 5(95):1-19. https:// doi.org/10.3389/fbuil.2019.00095

Paganoni S, D'Ayala D (2010) Experimental and computational validation of dissipative prototype for the seismic protection of heritage buildings. Adv Mater Res 133-134:831-836. https://doi.org/10.4028/ www.scientific.net/AMR.133-134.831

Paganoni S, D’Ayala D (2014) Testing and design procedure for corner connections of masonry heritage buildings strengthened by metallic grouted anchors. Eng Struct 70:278-293. https://doi.org/10.1016/j. engstruct.2014.03.014

Peña F, Prieto F, Lourenço PB, Campos Costa A, Lemos JV (2007) \{O\}n the dynamics of rocking motion of single rigid-block structures. Earthq Eng Struct Dynam 36(15):2383-2399. https://doi.org/10.1002/ eqe.739

Rai DC, Singhal V, Raj SB, Sagar SL (2016) Reconnaissance of the effects of the M7.8 Gorkha (Nepal) earthquake of April 25, 2015. Geomat Nat Hazards Risk 7(1):1-17. https://doi.org/10.1080/19475 705.2015.1084955

Romão X, Costa AA, Paupério E, Rodrigues H, Vicente R, Varum H et al (2013) Field observations and interpretation of the structural performance of constructions after the 11 May 2011 Lorca earthquake. Eng Fail Anal. https://doi.org/10.1016/j.engfailanal.2013.01.040

Sorrentino L, AlShawa O, Decanini LD (2011) The relevance of energy damping in unreinforced masonry rocking mechanisms. Experimental and analytic investigations. Bull Earthq Eng 9(5):1617-1642. https ://doi.org/10.1007/s10518-011-9291-1 
Publisher's Note Springer Nature remains neutral with regard to jurisdictional claims in published maps and institutional affiliations.

\section{Authors and Affiliations}

\section{Linda Giresini $^{1}$ (D) Fabio Solarino ${ }^{1} \cdot$ Francesca Taddei $^{2} \cdot$ Gerhard Mueller $^{2}$}

Fabio Solarino

solarino.fabio@gmail.com

Francesca Taddei

francesca.taddei@tum.de

Gerhard Mueller

gerhard.mueller@tum.de

1 Department of Civil and Industrial Engineering, University of Pisa, 1- 56121 Pisa, Largo Lucio Lazzarino, Italy

2 Lehrstuhl Fuer Baumechanik, Technical University of Munich, Munich, Germany 